\title{
The Study on the Influence of Fixed Asset Investment and Foreign Trade to the Economic Growth of Ningbo---Based on VAR Model
}

\author{
Zhenbo Li, Danping Yang \\ Ningbo University, Ningbo, China \\ lizhenbo163@163.com
}

Keywords: Fixed Asset Investment, Foreign Trade, Economic Growth.

\begin{abstract}
The relationships between fixed asset investments, foreign trade and economic growth have become important issues on today's academia. This article aims at research the interaction between the fixed asset investments, foreign trade and economic growth, and use Ningbo which is an important port city of China for instance, trying to find out the degree of influence. Through using VAR model as the tool of empirical analysis, and finally put forward policy recommendations to the benign development of Ningbo economic based on the three variables.
\end{abstract}

\section{Introduction}

This article from the relationship between economic growth and investment in fixed assets and total import and export perspective, analyzes how the foreign trade and investment in fixed assets impact on economic growth. By researching this, we can provide ideas and suggestions for Ningbo' foreign trade and economic growth.

\section{Ningbo Foreign Trade, fixed asset investment and GDP Situation Analysis}

Chen Xiushan, Zhang Yun (2010) considered that the so-called regional economic growth can be measured by (GNP) or per capita gross national product[1]. While in practice, currently most of the world countries and regions in the measurement of economic growth indicators replace the GNP with GDP. Meanwhile we found that a great part of the investment factor is fixed asset investment, so you can replace investment index with fixed asset investment index[2]. This paper uses the value of GDP to measure economic growth and the value of fixed-asset investment. GDP calculated by expenditure approach is relevant to investment, consumption, government purchases, and foreign trade and other economic factors. So we can analyze these factors to study the effects of on GDP.

Lin et al. (2001) by using improved method considered the different roles in the economic operation between exports and imports and the mutual influence relationship of economic variables [3]. And Liu Xianghong (2013) etc. by fixing asset investment, achieving existing assets updates and technical progress play a vital role to further adjust the economic structure, enhance the economic strength and speed up economic development[4].

From these we can find there are some shortcomings and deficiencies in current researches. First, there are few literatures having related research on a smaller range of city and the region. Second, the present study is lack in investment in fixed assets. Third, the current researches built on taking economic growth as the dependent variable and the fixed asset investment or foreign trade as an argument based on the model.Drawing on the basis of theoretical research, this paper intends to analyze the relationship between fixed asset investment, foreign trade and economic growth from the perspective of a comprehensive description, using Ningbo' fixed asset investment and foreign trade and GDP data from 1997 to 2013, which is combined with the theoretical basis and using widely VAR model [5].

From "Ningbo Statistical Yearbook" we can find that foreign trade has achieved rapid development during 17 years. Since the reform and opening up, Ningbo's gross domestic product has grown to 712.8 billion yuan in 2013 from less than 3 billion yuan the early stages of reform and opening up. Also, total export-import volume of Ningbo has rose from less than 100 million dollars in 1978 to 100.3 billion dollars in 2013[6]. The rapid economic growth in Ningbo is tightly tied to 
the rapid construction of Ningbo, whose aggregate investment in fixed assets has kept the annual average growth of nearly $20 \%$ in more than 30 years.

\section{Data Sources and Model selection}

In the empirical analysis, the paper selects from the range 1997 to 2013 of Ningbo City and select GDP, fixed assets investment (GT) and foreign trade (FT) as the research object, and the original data are from the "Statistical Yearbook of Ningbo City," and "Ningbo Economic and Social Development Statistics Bulletin." Every year. In addition, we take natural logarithm for GDP, WM and GT three variables.In terms of model selection, the paper makes use of the widely used VAR model to carry on the empirical analysis. In the form of simultaneous equations using natural regression model, in each equation of every model, the endogenous variables regress lagged values of all endogenous variables model to estimate the dynamic relationship between all the endogenous variables.

\section{Empirical Analysis}

Sequence Diagram Analysis. We judge the tendency by sequence diagrams. Figure shows that LnGDP, LnGT and LnWM are non-stationary time series three variables, and the same in trends and direction. There may be some long-run equilibrium relationship.

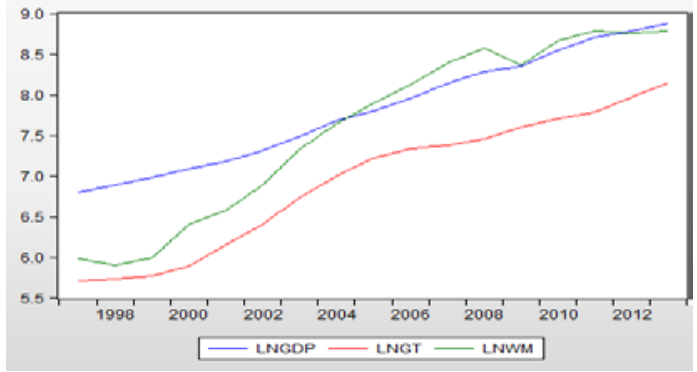

Fig. 1, Fig. 4 LNGDP LNGT and LNWM sequence diagrams

Lag order to determine. The greater the lag order representatives the higher integrity of models and the smaller freedom of models. Lag order determination result was obtained by Software, as shown in Table 1.

\begin{tabular}{ccccccc}
\hline \hline Lag & LogL & LR & FPE & AIC & SC & HQ \\
\hline \hline 0 & -0.825441 & NA & 0.000334 & 0.510059 & 0.651669 & 0.508550 \\
1 & 66.38227 & 98.57132 & $1.48 \mathrm{e}-07$ & -7.250970 & -6.684530 & -7.257004 \\
2 & 83.36820 & $18.11832^{\star}$ & $6.21 \mathrm{e}-08^{\star}$ & $-8.315760^{\star}$ & $-7.324490^{\star}$ & $-8.326319^{\star}$ \\
\hline \hline
\end{tabular}

\footnotetext{
* indicates lag order selected by the criterion

LR: sequential modified LR test statistic (each test at $5 \%$ level)

FPE: Final prediction error

AIC: Akaike information criterion

SC: Schwarz information criterion

$H Q$ : Hannan-Quinn information criterion
}

Table 1 The results of lag order

We can see that there is more than half of the criteria elected lag order for the second order, the model can be defined as the lag order of two bands.

AR test and ADF smooth test. In this paper, we use AR root test method for stability testing. Test results are shown in Table 2. And from AR root model we can know that the reciprocal value of six roots die all fall inside the unit circle, which shows that the model is stable. The ADF test results also show that the difference variable is stable after the treatment, as shown in Table 2. And we can know that LNGDP, LNGT and LNWM are I (1) series. 


\begin{tabular}{ll}
\hline \hline Root & Modulus \\
\hline \hline 0.987913 & 0.987913 \\
$0.691830-0.290127 \mathrm{i}$ & 0.750201 \\
$0.691830+0.290127 \mathrm{i}$ & 0.750201 \\
$0.231576-0.531134 \mathrm{i}$ & 0.579423 \\
$0.231576+0.531134 \mathrm{i}$ & 0.579423 \\
-0.042823 & 0.042823 \\
\hline \hline
\end{tabular}

No root lies outside the unit circle.

VAR satisfies the stability condition.

Table 2 AR tests of LNGDP, LNGT and LNWM variables

Inverse Roots of AR Characteristic Polynomial

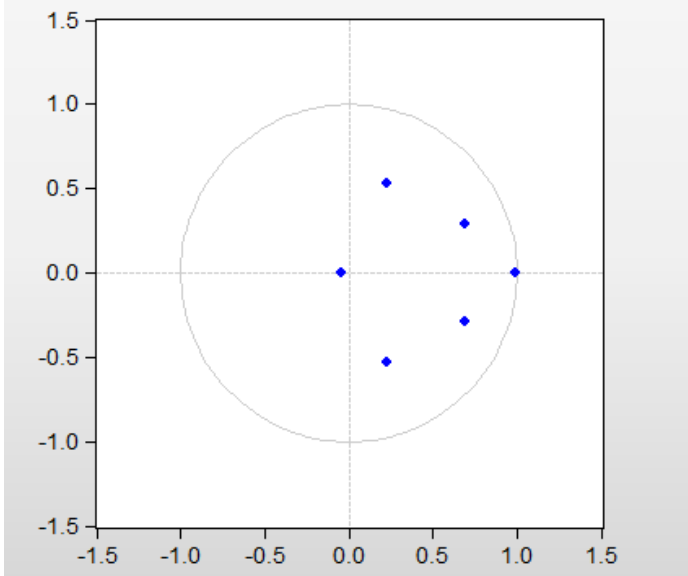

Fig. 2 AR test root distribution

Table 3 LNGDP LNGT, LNWM ADF test results

\begin{tabular}{|c|c|c|c|c|}
\hline Variable & Test Type & ADF test value & Critical value of $10 \%$ significance & Conclusion \\
\hline D(LNGDP) & $(\mathrm{C}, 0,0)$ & -3.047972 & -2.681330 & Smooth \\
\hline D(LNGT) & $(\mathrm{C}, 0,0)$ & -2.284482 & -1.603693 & Smooth \\
\hline D(LNWM) & $(\mathrm{C}, 0,0)$ & -2.992083 & -2.186330 & Smooth \\
\hline
\end{tabular}

\section{VAR model estimates}

Considering various factors, we chose model: DLOG (GDP)=DLOG(GT)+DLOG (WM)+C

Table 4 VAR value table

\begin{tabular}{|c|c|c|c|}
\hline & DLNGDP & DLNGT & DLNWM \\
\hline DLNGDP(-1) -0.147395 & (0.46309) [-0.31828]-0.154822 & $(0.82606)$ [-0.18742]-2.933967 & $(1.21950)[-2.40588]$ \\
\hline DLNGDP(-2) -0.553762 & $(0.42145)[-1.31395] 0.077114$ & $(0.75177)$ [ 0.10258$]-2.686594$ & $(1.10983)[-2.42073]$ \\
\hline DLNGT(-1) -0.076506 & (0.23358) [-0.32753] 0.805978 & $(0.41666)$ [ 1.93437$]-0.835961$ & $(0.61511)$ [-1.35905] \\
\hline DLNGT(-2) 0.390169 & $(0.22008)[1.77283]-0.494170$ & (0.39258) [-1.25878] 1.693722 & $(0.57956)[2.92245]$ \\
\hline DLNWM(-1) -0.092044 & $(0.11267)$ [-0.81695] 0.282393 & $(0.20097)$ [ 1.40512$] 0.135145$ & $(0.29669)[0.45550]$ \\
\hline DLNWM(-2) 0.050851 & $(0.12344)$ [ 0.41195$]-0.025721$ & $(0.22019)[-0.11682] 0.332385$ & $(0.32506)[1.02254]$ \\
\hline 0.193617 & $(0.07156)[2.70573] 0.071763$ & $(0.12764)[0.56221] 0.750504$ & $(0.18844)$ [ 3.98275] \\
\hline R-squared & 0.533854 & 0.632028 & 0.767192 \\
\hline Adj. R-squared & 0.134300 & 0.316624 & 0.567642 \\
\hline Sum sq. resids & 0.011526 & 0.036675 & 0.079929 \\
\hline S.E. equation & 0.040578 & 0.072383 & 0.106857 \\
\hline F-statistic & 1.336124 & 2.003867 & 3.844617 \\
\hline \multicolumn{2}{|c|}{ Akaike information criterion } & -7.192731 & \\
\hline \multicolumn{2}{|l|}{ Schwarz criterion } & -6.234145 & \\
\hline
\end{tabular}

It can be found that in the first period WM coefficients is greater than the GT, which shows that in the short term impact on GDP of foreign trade will be greater than t fixed asset investment. So its role in stimulating economic growth isn't an immediate. Fixed asset investment impacts on GDP relatively slow, meanwhile stimulating is enormous. The impact of foreign trade on GDP in the short term is great while decays immediately later. GDP growth has a leading role in fixed asset investment, which is inferior to foreign trade. Furthermore VAR model also shows that the impact 
of GDP changes for foreign trade is huge [7]. The impact of 2008 economic crisis on foreign trade continues since [8].

Pulse Analysis. We focus on that when VAR model under some impact, this system will produce what kind of the dynamic changes. In Figure 3 intermediate solid line is the impulse response function, which represents the dynamic response of the impact of each variable, and the dotted line on both sides is the confidence band of impulse response function plus or minus two times of the standard deviation indicating the possible range. Impulse response function all tend to 0 , which proves that the model is very stable.

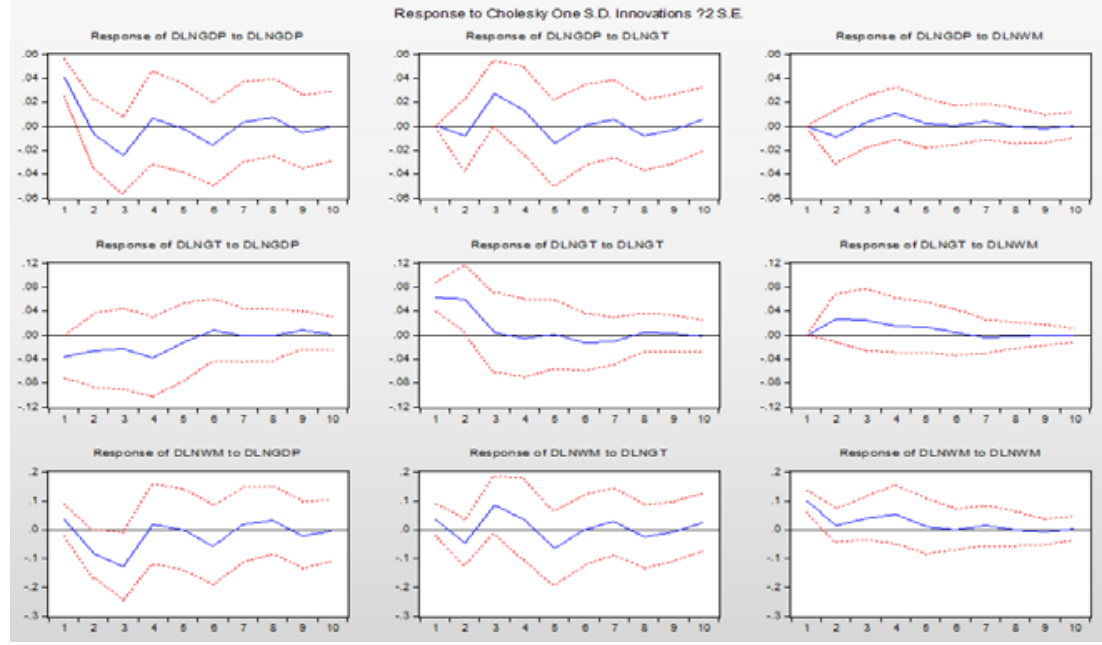

Figure 3 Impulse response analysis

\section{Conclusion and Suggestion}

In summary, foreign trade and investment in fixed assets have varying degree of impact on economic growth. Fixed asset investment effect on economic growth more evident, but will time lag result from investment in fixed assets. Foreign trade and investment in fixed assets must be interrelated, and strong development of foreign trade will lead to increasing fixed asset investment projects.

First, optimize fixed assets investment structure. Increase the project investment high-tech manufacturing and new materials manufacturing. The rational distribution of investment in fixed assets in the three industries is important. Increase investment in basic industry and emerging industry [9]. Second, increase the income to stimulate consumption growth. The stimulating effect of the investment to economic growth on the one hand is driven by their needs, while more important aspect is the size of investment multiplier determined by the marginal propensity to consume. Third, encourage technological upgrading of export industrial and form ownership advantages. Industrial upgrading of Ningbo' export industry should be given priority. Replace the traditional quantity with the quality to win. Focus on accumulating the unique ownership advantages, and continue to gain market through the development of monopoly [10]. Finally, rational distribution of three industrial structure and promoting sustainable development are important. As China's southeastern coastal city, Ningbo should carry out industrial restructuring and focus on the quality of economic growth.

\section{References}

[1] X. Chen and K. Zhang. Regional Economic Theory. Beijing: Commercial Press, 2010: 154-170.

[2] M. Lu. International Direct Investment Location Determinants. Nanjing: Nanjing University Press, 2000: 42-46.

[3] Y. Lin, Y. Li. Necessary Corrections - Reexamination of Foreign Trade and Economic Growth. International Trade, 2001, 9: 21-26. 
[4] X. Liu. Empirical Analysis on Relationship of Dalian Economic Growth and Fixed Asset Investment Based on VAR Model. Liaoning Economic, 2013, 11: 29-31.

[5] K. Zhang. The Coordinated Development of Industrial Structure and Urbanization, Regional Economy. Economists, 2004, 04: 9-14.

[6] T. Gao. Econometric Analysis and Modeling: Eviews Applications and Examples (2nd edition). Beijing: Tsinghua University Press, 2009: 68-135.

[7] B. Fan. Empirical Study of Chinese Exports Contribution to Economic Growth Rate: Year 1952-2003. International Trade Issues, 2005, 8: 5-9.

[8] J. Wu. China's Economic Growth Mode Selection. Shanghai: Shanghai Far East Press, 2006.132-136.

[9] G. Mao. Some Thinking to Promote Growth Mode Transformation of Ningbo Economic. Zhejiang Today, 2005, 03: 35.

[10] W. Lu and L. Zhang. Our Domestic Demand, External Demand and Economic Growth - An Empirical Analysis Based on VAR Model. Journal of Shanxi Finance and Economics University, 2010, 02: 32-33. 